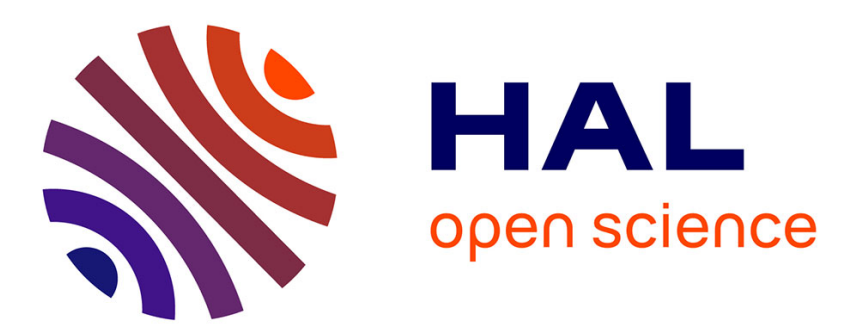

\title{
Specification management for the cost constraint optimisation in microelectronic design
}

\author{
Magali Mauchand, Nicolas Perry, Alain Bernard
}

\section{To cite this version:}

Magali Mauchand, Nicolas Perry, Alain Bernard. Specification management for the cost constraint optimisation in microelectronic design. International Journal of Manufacturing Technology and Management, 2008, 15 (3/4), pp.284-297. 10.1504/IJMTM.2008.020171 . hal-00476628

\section{HAL Id: hal-00476628 \\ https://hal.science/hal-00476628}

Submitted on 2 Jul 2019

HAL is a multi-disciplinary open access archive for the deposit and dissemination of scientific research documents, whether they are published or not. The documents may come from teaching and research institutions in France or abroad, or from public or private research centers.
L'archive ouverte pluridisciplinaire HAL, est destinée au dépôt et à la diffusion de documents scientifiques de niveau recherche, publiés ou non, émanant des établissements d'enseignement et de recherche français ou étrangers, des laboratoires publics ou privés. 


\title{
Specification management for the cost constraint optimisation in microelectronic design
}

\author{
Magali Mauchand
}

Manufacturing Engineering Team,

Laboratoire de Génie Industriel et Production Mécanique,

ENSAM, CER Metz, 4, rue Augustin Fresnel,

Metz 57 070, France

E-mail: magali.mauchand@metz.ensam.fr

\section{Nicolas Perry* and Alain Bernard}

Virtual Engineering for Industrial Engineering team,

Research Institute on Communication and Cybernetic of Nantes,

UMR CNRS 6597,

Ecole Centrale Nantes, 1, rue de la Noé,

Nantes 44321, France

E-mail: Nicolas.Perry@irccyn.ec-nantes.fr

E-mail: Alain.Bernard@irccyn.ec-nantes.fr

${ }^{*}$ Corresponding author

\begin{abstract}
In the preliminary design phase the integration of the economic constraints of a product is a difficult engineering task since there is a real lack of dedicated tools. This paper illustrates a specification software solution method making it possible to meet this need, applied to the microelectronics field.
\end{abstract}

Keywords: cost evaluation; microelectronic; software model integration; cost methods.

Reference to this paper should be made as follows: Mauchand, M., Perry, N. and Bernard, A. (2008) 'Specification management for the cost constraint optimisation in microelectronic design', Int. J. Manufacturing Technology and Management, Vol. 15, Nos. 3/4, pp.284-297.

Biographical notes: Magali Mauchand is an Ecole Centrale de Nantes (fr) Engineering school student who graduated in 2003. She is pursuing her $\mathrm{PhD}$ based on the integration of economic aspects at the early engineering phase of a product development. She started her PhD in System Plus Company, focusing on microelectronic products, and she is now working at the ENSAM de Metz on mechanical products.

Nicolas Perry received his $\mathrm{PhD}$ in Mechanical Engineering from the University of Nantes and Ecole Centrale de Nantes in 2000. He is an Associate Professor at Ecole Centrale de Nantes and relies to the Research Institute on Communication and Cybernetics of Nantes (IRCCyN). His research topics focus on Virtual Engineering, Knowledge Management and KBE as Decision 


\title{
Specification management for the cost constraint optimisation
}

\begin{abstract}
Alain Bernard works at the Ecole Centrale de Nantes, and manages research at the IRCCyN (Virtual Engineering for Industry). He was the Vice-President of AFPR (French Rapid Prototyping Association) and its representative in Global Alliance of Rapid Prototyping Associations (GARPA). From 1996 to 2001, he was a Professor at the CRAN laboratory (Research Centre for Automatic Control of Nancy) in Nancy, where he managed a research group (ICF) on mechanical and production engineering. His main research topics are related to reverse engineering, knowledge-based systems for computer-aided process planning (applied to machining, rapid prototyping and laser digitising), and product and process modelling. He received his $\mathrm{PhD}$ in 1989, on $3 \mathrm{D}$ feature-based manufacturing of forging dies.
\end{abstract}

\section{Introduction}

Traditional approaches to product development lead to long product development cycles and difficult cost control. Nowadays the desired approach to product development is a concurrent of an emphasis on cost control. Needs for economic and technical product evaluations are compulsory in the design process for the complete product life cycle (Giannopoulos et al., 2003; Liu and Basson, 2004). However, methods for requirement definition integrated costing methods are poorly developed on the market. A design strategy should minimise cost and time while maximising quality. This paper describes a modelling strategy to assist manufacturers in optimising these objectives.

Information and management systems must be developed in order to support the specification and to analyse the considered solutions (Bachelet, 1994; Perry and Bernard, 2003).

The microelectronic field is characteristic of firms called 'fabless IC', the design departments are located outside the production sites and have few links with the latter. They focus on design and contract out the production stages to silicon wafer manufacturers or foundries ( $\mathrm{Lu}$ et al., 2004). This outsourcing phenomenon came from the need of reactivity, to earn more money and to keep competitive skills (Helo, 2004). Moreover outsourcing strategies in general are commonly linked to the product life cycle (Hilmola et al., 2005). Also an operating mode must be set up in order to design circuits that are feasible by the production line recommended for the manufacturing.

The main parameters of the life cycle of an electronic product for the public market are, on the one hand its really short lifespan, and on the other hand, the very fast evolution of technologies (shrinks), and also the work requirements for the research and development phase lead. For instance, product life cycles in the PC industries were approximately one year in the middle of the 1980s but by 1997 they had shrunk to approximately three months (Curry and Kenney, 1999). In electronics there are some systems with a long lifespan such as the ones developed for military and aviation applications. In these cases the design problem must include the system maintenance and enable a valorisation of the economic impact of decisions (Riedel et al., 1999).

Enterprises face the problem of perpetual innovation with the renewal of technologies and world-wide logistic integration to deliver to customers throughout the world. In the PC market, price and time are closely connected (Curry and Kenney, 1999). Consequently subcontracting capacities or competences have become common practices 
in the microelectronics business. "Companies need to be proactive for uncertainties of the market in a productive way" (Helo, 2004). The general axes of competitiveness are time-based competition, increasing product variety and new technologies.

These problems will be illustrated and addressed in the framework of the cost constraint optimisations, within the microelectronic design field. Based on $\mathrm{PhD}$ collaboration with System Plus Company, a software developer for electronic product cost or price evaluation, a method will be proposed and analysed for industrial deployment.

\section{Microelectronic field context}

The keystone of the global approach is to determine the basic elements on which decision-making tools can be built. Moreover, the actor's knowledge background also has to be well understood. Designers have to face and solve economic problems without sufficient skills.

The first step of this work is the generation of a cost or price estimate model. System Plus is a company that develops and edits cost estimation software (costing) or sale price determination (pricing) in the microelectronics field. Four software solutions were developed and/or sold, which answer various aspects of the costing or pricing targets from the silicon wafer (microchips production) to the finished products (electronic boards or cell phones). The description of a generic economic model used to determine the product industrial value is the goal of the $\mathrm{PhD}$ project carried out in collaboration between this company and the IRCCyN laboratory.

The experiment of microelectronic parts, and more precisely the integrated circuits and the electronic boards, were highlighted by the development of software dedicated to these elements. Due to historical independent developments, the expert's knowledge is hidden within the heart of these applications. Moreover, each structure, cost models and specific concepts are independent and not fully documented. To guarantee their reliability, they were specified and tested by experts from the technological field and experts in data processing. As a result, major work is necessary, dealing with the software knowledge extraction, analysis and formalisation to transcribe the infrastructure (basic elements) of each solution and check coherency and consistency (Du Preez et al., 2005).

Obviously, this approach cannot be compared to the accounting method where the principal concern is the total result of the company. Here, the designer has to create a realisable (feasible) product and meet all the technical specifications and constraints. Design is

\footnotetext{
"the creative activity which consists in working out a project, or a part of the elements that compose it, on the basis of the expressed needs and means existing and technological possibilities with an aim of creating a product or a service" (GDT, 2006).
}

All necessary information is available in order to establish a costing. But it remains to be able to put in accordance their objectives with the costs of the product during its design. The distribution of the data-gathering sites (departments, services, continents) is a key-point approached in several papers such as those by Michael Wahl, who has built a cost model based on information (Wahl et al., 2000a,b). 


\section{A lack of dedicated tools for the engineers in charge of cost control}

\subsection{Statement: a new product life cycle management, new costing approaches}

Manufacturing industries (having a great number of operating human resources) have gradually moved towards engineering industries (requiring more and more thinking resources). The distribution of the realisation costs of a product (direct and indirect costs) have moved in parallel, being reversed compared to the economic model of the last few years. One of the principal reasons comes from the fact that studies delay are longer for a batch production with weak dimensions within a context where the environment tends towards short life cycles of product. Consequently, the methods (e.g. cost accounting or analogical approaches), developed when the distribution of the costs resulting primarily from direct costs are no longer relevant.

Over the last few years there have been significant improvements on the level of concepts, methods and general approaches of cost determination of a manufactured product. It proves that the methods which emerged from it, have not yet reached a sufficient level of maturity (Berliner and Brimson, 1998). Problems persist, such as implementation steps that are very little specified and global, and that are not able to provide relevant solutions. None of these approaches propose a deployment methodology of already well established and well controlled (e.g. allowing the extraction of cost drivers).

\subsection{Result: a lack of tools for cost estimation dedicated to engineering}

In the preliminary phases of the product life cycle, the cost control is a major performance criterion of a firm's competitiveness. Consequently, the cost (and the cost management throughout the product and process life cycle) is as crucial and dominant as the technical requirements defined in the phase of product specifications (Mevellec and Lebas, 1998). The appropriate tools that the engineers require to assist them in the integration of these economic aspects during the design phase are hard to find. From now on, the control of the costs is the indispensable condition of success, since the technical decisions made in phase of design engage on average more than $70 \%$ or even $80 \%$ of the final cost of the product according to the type of production (Perrin, 1996). We should define a methodology of specification management which corresponds only to the technical specifications and other elements defined in the schedule of conditions of the product to support the cost estimation of the design alternative solutions under consideration by the designer.

\section{Costing approaches}

\subsection{Cost estimation methods}

This paper does not aim to describe in detail the methods of cost calculation or of cost estimation, so only a short review of the three main and most used approaches is presented. 
- the analogical methods are based on the experiment of similar projects/products/functions already developed

- the parametric methods incorporate cost information relevant to the functions of the products

- the analytical methods detailed by part and by operation the cost of the products/process.

\subsection{Necessary measurements}

These various methods impact differently the various stages of the project life cycle and thus have applications dependent very largely on the maturity of design/industrialisation of the concerned product.

In addition, the choices made at the initial stages of the project impose technical solutions in terms of materials, realisation means, solution architectures, etc.

It is obvious that any modification will become increasingly expensive during the progress of the project. The project collaborators track the errors as soon as possible and collaborative working methods try to reduce to the maximum these risks of errors. For each identified error, an indicator of the cost solutions is evaluated in order to see the respect of the global required for the project.

\subsection{Methods of cost management during the design}

Methods of cost management for controlling the design by performance and cost objectives ('Conception à coûts objectifs' (CCO), Design-to-X, etc.) were set.

The Design-To-Cost (DTC): the DTC is thus defined by E.B. Dean:
"Design-to-cost is a method of controlling costs by establishing cost goals at specified levels of a work breakdown structure and then requiring the project to make trades which will ensure that the system built will meet those cost goals. In design-to-cost, the cost goals are added to the existing requirement set to form an augmented requirement set" (Dean, 1990).

' $C C O$ ': as the Value Analysis, The expression DTC was first coined in the USA. The CCO is a French method making it possible to design a product while imposing at first a ceiling cost (Delafollie, 1991). Another more precise definition can be evoked. The 'CCO' can be defined as

"a principle of action aiming at establishing rigorous objectives as of the stage of system development and at authorizing cost/performance compromises to allow the respect of these objectives" (Petitdemange, 1991).

The standard X 50-150 defines the $\mathrm{CCO}$ as a method of project management based on:

- the assignment of an objective ceiling price or cost (predetermined and fixed independently of all references to costs of a technical solution)

- specific procedures and arbitration rules defined at the beginning of the project by the organisation

- the identification and the description of the user's need in open and negotiable form (e.g. the schedule of conditions). 
The CCO also called 'Conception pour un Coût Global' (CCG) is a methodological tool which makes it possible to reach industrial competitiveness by the control of the value.

Target costing: the target costing is applied within the framework of a production control mode in Just-In-Time (JIT). In the field of accountancy, the target cost is the cost objective defined by taking into account the market rates and the market conditions. This objective is equal to the difference between the selling price likely to ensure a certain market share and the desirable margin (GDT, 2006). It is a cost obtained by withdrawing the desired result of a sales turnover based on an evaluation of the contract prices and production volumes engineering and marketing. The objective cost is not based on the initial cost of the product but rather on the cost which it will reach when at cruising speed (Ansari et al., 1997).

Based on four different software application models, we want to concentrate the knowledge they used to process to develop only one model for cost estimation of microelectronic products and/or systems.

Activity-Based Costing (ABC)/Activity-Based Management (ABM) is a cost management method developed by Cooper and Kaplan at the beginning of the 1990s. In the ABC system, accountants work to allocate the cost of each activity (such as purchasing, production, engineering and so on) to the cost object that induces the activity. According to proponents, ABC has two objectives: to provide detailed information that describes the cost and consumption of activities owning to the organisation, and to provide accurate information to managers to improve their decisions (ABM) (Sheu et al., 2003).

Theory of Constaints (TOC)/Throughput accounting is based on Goldratt's idea that the main constraints in organisations are often not physical ones but policy constraints. TOC manages three operational performance measures that are throughput, inventory and operating expenses. The focus of TOC is then to maximise throughput while decreasing inventory and operating expenses. The throughput accounting is referred to as the accounting system proposed by TOC, it is seen as the opposite of conventional accounting and ABC (Sheu et al., 2003). TOC could give indicators to decide what the product mix will be (what to produce and how much) or to decide outsourcing (Hilmola, 2001).

Sheu et al. show how to use these two last methods to take the decision to make or buy a product. It seems that these approaches can be applied to routine design. Moreover Hilmola emphasises that Throughput accounting can be applied to the evaluation process of new product alternatives (Hilmola, 2004).

\section{Steps of unified meta-model/concept construction}

A specific approach for creating knowledge-based engineering project is has been developed by our research team and illustrated in Figure 1 (Candlot et al., 2005). This figure represents the steps of implementation, formalised in our methodology for the construction of models. This is a three-phased methodology:

- First of all, the fundamental elements of the structure must be identified. This corresponds to the Infrastructure Definition Phase (identification, extraction, structuring and formalisation). 
- Relationships between these elements are then identified, and the elements are deployed in a coherent manner to optimise their efficiency. This is the Architecture Phase (refinement, development, diffusion, maintenance).

- The third phase is a software specification generation by a validated knowledge-based application.

Figure 1 Loop cycle of the integration step

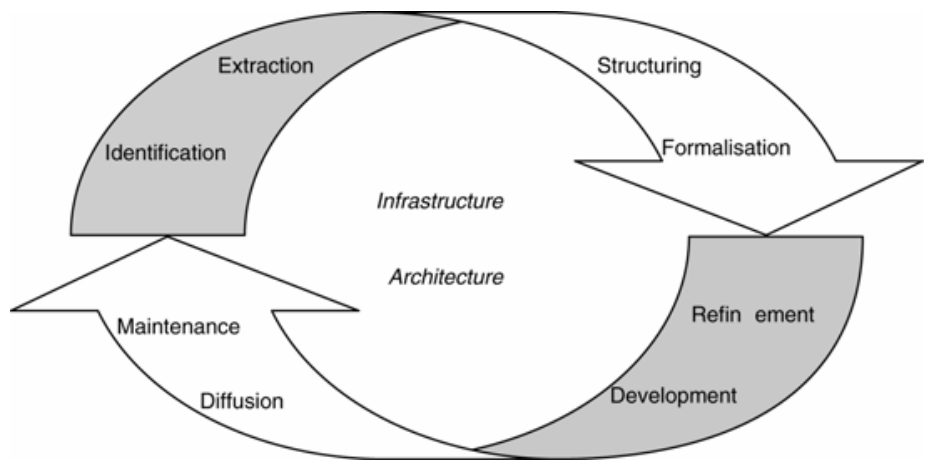

Source: Candlot et al. (2005).

\subsection{Infrastructure}

The goal for defining the infrastructure in the development of applications is to identify the elements (concepts) which make up the application and to define them in terms of attributes, methods and relations between these elements. This definition is summarised by the following stages:

Identification: the stage of identification consists in specifying the problem which is posed in order to fix the limits of the applicability, to locate all the concepts handled in this field: key words, knowledge, activities, tasks, constraints, reasoning, etc. It also aims at surrounding and justifying the applications to be set up in terms of deliverable, times, resources to be affected and costs. In other words, this stage enables us to identify the basic elements which will be used to build infrastructure blocks of the application field.

Extraction: the extraction consists in counting the concepts identified in the preceding stage. These concepts being little or badly, not defined, this stage aims at enlightening them, at identifying existing associations between them in order to make sure that all the concepts necessary for the construction of the application are defined. It also aims at specifying the activities in which they get involved.

After the stage of finished structuring the infrastructure of our application field is defined.

Structuring: the structuring focuses on semantically organising the infrastructure of the field. It resides in grouping together the various concepts according to points of view. The latter can be of a functional, geometrical and structural nature. This organisation enables on the one hand a formalisation of the processes, and on the other hand, the construction of an expert reference frame and a reference frame of the field. 
The structuring will also relate to the representation of these concepts which can be either textual as certain methods of knowledge management allow it or graph as is the case of Methodology for Knowledge System Management (MKSM) methods.

Formalisation: the goal of the formalisation stage is to syntactically represent the semantic concepts using a standard formalism such as for example, UML, the Petri nets, the logic, etc. It is also composed of data models and sequence diagrams. A semantic and syntaxic systematic questioning is carried out: What does this concept means? Are there similar words or concepts? All this work defines the architecture of the field. This becomes the infrastructure of the final application software.

\subsection{Architecture}

The definition of the application architecture consists in defining how the blocks that compose the infrastructure are articulated and associated between them. This step is illustrated by the following stages:

Refinement: the refinement aims to preserve only the most essential, relevant concepts in comparison with the problem which is posed. During this stage, it is necessary to identify the key concepts which must be shared by all the actors in collaboration. This phase is thus dedicated to the evaluation of the relevance of the concepts and their relationships.

Development specifications: the purpose of this stage is to implement the structures defined in the preceding stages in a computer application. For instance, this implies the translation of the structures in terms of classes and attributes in a computer language. It is also a question of defining the various interfaces of the application and of developing servers of knowledge and procedures of decision-making aids.

Diffusion: the diffusion consists in putting the application at the disposal of the end-user in order to test it. It will be done by an installation of the application on all the stations of the company, by the organisation of training courses and by the installation of a follow-up for the users. A forum of discussion on its starting can also be created.

Maintenance: the last stage of the step aims to define procedures to be put in action to ensure the maintenance of the information inheritances and to evaluate the relevance of the application through experiment feedback on its use by the personnel of the company. This implies the identification of the strong points as well as weak points of the application. The stage of maintenance must also solve the problems of update and the changes of the original specifications.

\section{Our case}

\subsection{Industrial tools background}

Let us first picture the background of the study. The four software applications developed by System Plus Company, synthesised in Table 1. 
- Virtual IC Fab: is based on the simulation of a wafer fabrication plant in order to calculate its costs and its selling price. This software enables the creation of data bases to simulate a clean room. Its principal characteristics are: to be dedicated to the manufacture of wafers and the associated products (integrated circuits), supported by three key-fields in a company which are the knowledge of the production, the system of purchase and the design of the circuits. It carries out a simulation of the outputs and cost variations according to the parameter time, simulations of production costs calculations of the IC, simulations of the selling price according to market fluctuations and creates a virtual wafer fabrication plant and calculates the wafer cost from real data. Moreover, a simulation on several levels of precision is feasible; it depends on the detail level of available information.

- IC purchaser: is a tool for costs and selling price estimation dedicated to integrated circuits. The cost calculations use parametric models extracted from analytical expertise. The passage from the cost to the selling prices is also based on parametric models. Thus, it has cost parameter generators, for example, for the generation of manufacture technology like Wafers, for cases generation. The database contains the following descriptive elements: technologies of wafer manufacture, encapsulation cases, wafer fabrication plants and component makers. The calculations carried out make it possible the construction of the manufacturing costs and to have an estimate of the selling price.

- SysCost: aims to precisely and rapidly quantify the production cost of an electronic system (compound of complete boards or subsystems), to evaluate and control the costs of a project and to carry out a precise estimate.

- WaCoFo: is used to analyse and predict production costs of semiconductor technologies. It calculates a wafer cost over one defined period, based on the modelling of the manufacturing unit (fabunit, workshop, workcentre description).

Table 1 Enters and outputs of the SysCost tool

\begin{tabular}{ll}
\hline Inputs & Outputs \\
\hline Flow, assembly schedules & Assembly and test costs \\
Bill of Material (BOM) & Raw cost \\
DB purchases & Manufacturing cost \\
& Selling price \\
\hline
\end{tabular}

In order to harmonise all this software under in a unique nutshell, we have tried to tackle this problem with the definition of a global model. It takes into account all the concepts and rules that are used in the existing software applications. Moreover, a method for the conceptual design stage has been developed in order to use the production costs models. This design, the dynamic use of the future tool based on the experience, a methodology implementing expert knowledge at production and design level is presented mixing cased based and rule-based reasoning (Rehman and Guenov, 1998). Moreover, the studies undertaken in the field of the foundry can enrich the development step of the cost estimate model (Delplace, 2004; Perry et al., 2004). 


\subsection{Meta-model identification phases}

The first stage of the implemented methodology consists in the extraction of the cost estimate models from the tools. Then an abstraction phase leads to the construction of a meta-model common to the various solutions suggested by the company System Plus. The last phase consists in reinforcing the semantics contained in the meta-model to extend the application fields.

The first methodological phase deals with the infrastructure modelling of System Plus applications; they integrate the very first constraints that were specified by the customer needs (first specification of the tools) and new concepts and models (each specific application makes integrating models whose aims vary from the original) (see Table 2 and Figure 2):

- cost calculation models configured within the software are parametric models or analytical models

- models of production flows take into account different degrees of complexity

- different scales of product (of the electronic chart to the chip)

- multi or mono products sites.

Table 2 Studied software application characteristics

\begin{tabular}{|c|c|c|c|c|}
\hline & Virtual IC Fab & IC purchaser & SysCost & WaCoFo \\
\hline $\begin{array}{l}\text { Application } \\
\text { field }\end{array}$ & Semi-conductor & Semi-conductor & $\begin{array}{l}\text { Electronic } \\
\text { board }\end{array}$ & Semi-conductor \\
\hline Cost method & Analytic & Parametric & Analytic & Analytic \\
\hline Product scale & Micro & Micro and multi & Macro & Micro \\
\hline Enterprise & Multiproducts & Mono-product & Mono-product & Multiproducts \\
\hline Flow structure & Complex & Complex & Linear & Complex \\
\hline
\end{tabular}

Figure 2 Typology examples: left $\mathrm{WaCoFo}$ - right SysCost

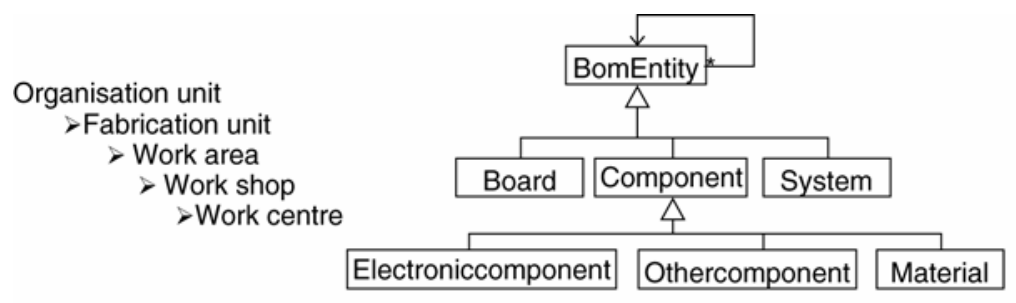

Thus the field infrastructure consists of all the calculation methods contained in the software solutions and the attributes of the products in their context. Their formalisation and their refinement make it possible to obtain the architecture of a more homogeneous and more complete cost model (see Figure 3).

The concepts of activity and process, entity and paper, resources (material and human) and of course cost and selling price are a representative panel of the main extracted concepts. This list is not exhaustive. An interaction exists between the industrial concepts and the prospective scientific tools. 
Figure 3 Example of an infrastructure definition of SysCost (see online version for colours)

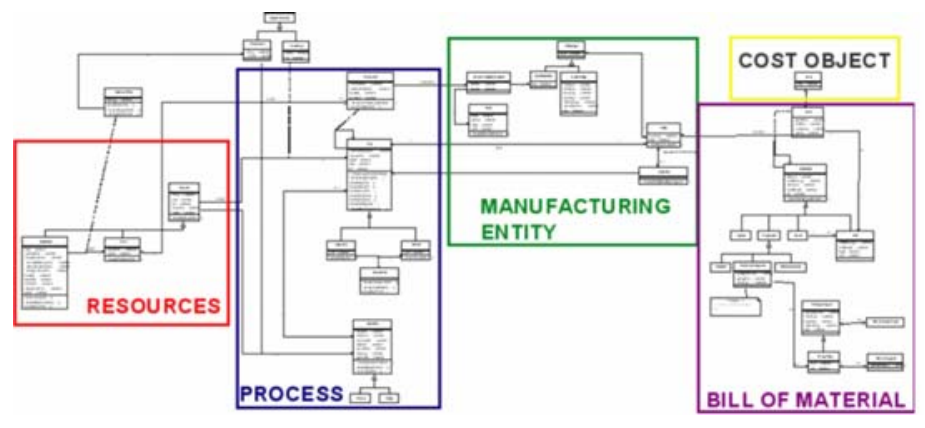

Various scientific research projects are concerned with the set of themes implemented here such as the management of production and management control (Mevellec, 2000; Mevellec and Lebas, 1998). In addition, it appears that concepts are employed in several tools without being directly definable. The expert language masks the real semantics of the concepts. It is important to ensure coherence between the latter (as well as the models which represent them) mainly on the aspects of covering the fields, constraints and contexts. It is essential to represent the bonds between the concepts. With this purpose, two aspects have to be approached:

- a static approach (e.g. the concept definition and bond formalisation by a class diagram)

- a dynamic approach (e.g. the use of the concepts through a sequence diagram or a SADT diagram).

The integration phase gives concrete expression to all the models and the concepts including the different tools published by System Plus. It makes it possible to confront the various partial approaches (realised by using a class diagram). It is also necessary to take into account the processes of usage of these concepts and the calculation methods in the System Plus tools (such as, e.g. a SADT diagram identifying the specific needs with each considered stage of the project life cycle). At this level a first methodological approach of deployment and use of the tool is formalised.

\subsection{Meta-models consolidation phases}

In the second phase, the architectural development relies on a semantic analysis that enriches and consolidates the meta-model so as to make it independent of a particular industrial sector. In addition, the methodological step of suggested use is reexamined and enriched to be independent of a specific application (see Figure 4). The definition of a common ontology with (Protégé, 2005) will try to ensure coherency and exhaustiveness.

An experiment feedback with the different concepts identification, their global coherency check using ontology and a confrontation with other industrial branches should make it possible to test the robustness of this approach. Interpretations of the final model are preconditioned by the fact that various methods and software tools have already been developed. However, they do not presuppose the final development that remains to be defined. Thus, all the model developments are carried out in interaction with the modelling of these various applications. 
Figure 4 Example of refinement with the notion of entity in SysCost enriched with the WaCoFo attributes

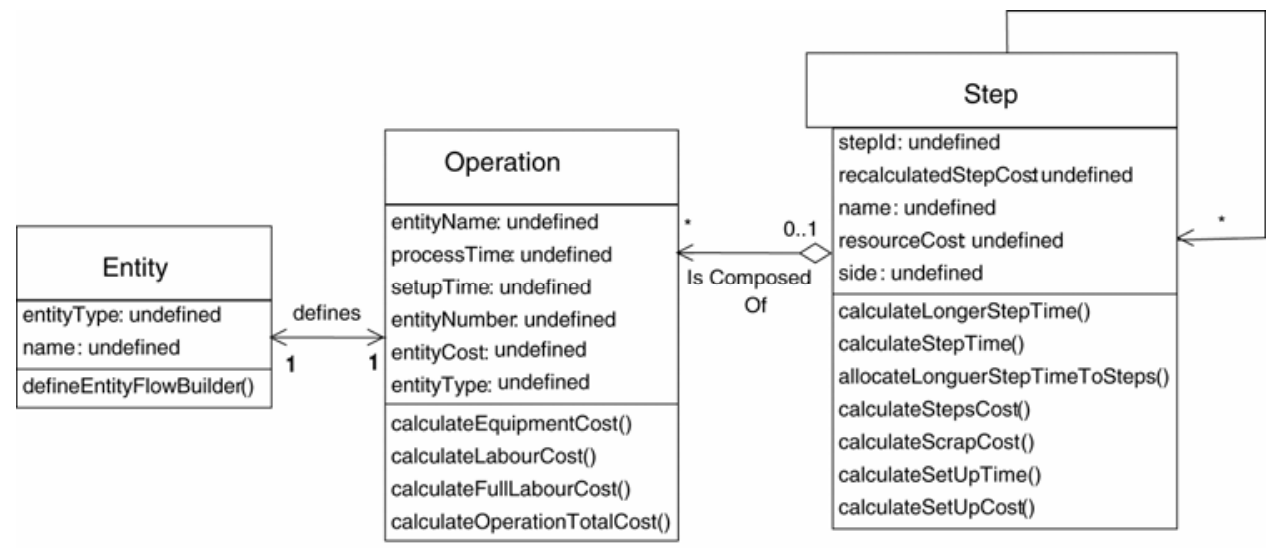

The implementation of the Architecture is thus closely related to the maturity of the comprehension of the Infrastructure. This becomes the final specification structure and rules for the new costing/pricing software to be developed (Table 3).

Table 3 Possible and used tools or for each phase

\begin{tabular}{lll}
\hline & \multicolumn{1}{c}{ Phase } & \multicolumn{1}{c}{ Tools } \\
\hline Infrastructure & 1 Identification & Software applications analysis \\
2 Extraction & Scientific community \\
3 Structuring & Microsoft Office \\
& 4 Formalisation & UML \\
Architecture & 5 Refinement & Objecteering (UML editor) \\
& 6 Specification & Not defined \\
& 7 Diffusion & Not defined \\
& 8 Maintenance & Not defined \\
\hline
\end{tabular}

\section{Conclusion and outlines}

The final model has not yet been attained, but partial area coherency and enrichment have been achieved. A major difficulty is the different initial objects used, without clear definition. Depending on the presence or not of the software developer, the exact 'spirit' of the object can be defined. Moreover, some documented elements (object attributes or calculation rules) do not correspond exactly to the real use or application of the software. The first specifications (when they exist) have been adapted but with no specification modification traceability.

The steps presented in this paper have a double objective:

- To structure the models and the concepts handled by the various tools developed by the System Plus Company, for cost as well as data-processing development. 
- To structure the meta-model for cost estimate of industrial products independently of its industrial branch. As this study was begun after the development of the software applications supporting these problems, it benefits from this first generalisation. The suggested methodological step, already tested, guides the construction of the implemented thesis postulate.

The prospects for this work relate to two-fold. On one hand, to continue to confront the general methodology proposed for knowledge-based projects specification with a real case, and improving it if necessary or judging its robustness. In addition, to apply this general approach of modelling recommended in this work to various industrial sectors, identifying any shortcomings and consolidating the generic approach. For the method evaluation, the definition of indicators and their measurement remain to be done. This can take place only by the identification of partners and real applications.

\section{Acknowledgements}

The authors would like to thank System Plus partners, who initiated this work, and the French National ANRT association that supports the cross research collaboration between industry and laboratories.

\section{References}

Ansari S.L., Bell, J.E. and The CAM-I Target Cost Core Group (1997) Target costing, the Next Frontier in Strategic Cost Management, Iwin, McGraw-Hill, New York, ISBN 0-7863-1053-7, pp.1-18.

Bachelet, R. (1994) 'DESI: Méthode d'évaluation de l'impact économique des choix techniques', Available at: http://www.ig2i.fr/rb/recherche/Communication_AFC_94/afc_cout.html.

Berliner, C. and Brimson, J.A. (1998) Cost Management for Today's Advanced Manufacturing, the CAM-I Conceptual Design, Harvard Business School Press.

Candlot, A., Ammar-Khodja, S., Mauchand, M. and Perry, N. (2005) 'Réflexion sur une approche systématique pour créer des structures de consolidation de l'information', 9ème Colloque National AIP PRIMECA, La Plagne, avril.

Curry, J. and Kenney, M. (1999) 'Beating the clock: corporate responses to rapid change in the PC industry', California Management Review, Vol. 42, No. 1, pp.8-35.

Dean, E.B. (1990) 'The design-to-cost manifold', International Academy of Astronautics Symposium on Space Systems Cost Methodologies and Applications, San Diego CA, USA, 10-11 May.

Delafollie, G. (1991) Analyse de la Valeur, Paris: Hachette Technique, ISBN - 2-01-017151-9.

Delplace, J-C. (2004) 'L'Ingénierie numérique pour l'amélioration des processus décisionnels et opérationnels en fonderie', PhD Thesis, University of Nantes and Ecole Centrale de Nantes, October, Speciality Production and Industrial Engineering.

Du Preez, N., Perry, N., Candlot, A., Bernard, A., Uys, W. and Louw, L. (2005) 'Customised high-value document generation', CIRP Annals, Vol. 54, No. 1, pp.123-126.

GDT (2006) Le Grand Dictionnaire Terminologique, Available at: http://www. granddictionnaire.com.

Giannopoulos, N., Roy, R., Taratoukhine, V. and Sarasua-Echeverria, A. (2003) 'Embedded systems software cost estimating within the concurrent engineering environment', CE03: the Vision for the Future Generation in Research and Applications, ISBN 9058096238 , pp.352-357. 
Helo, P. (2004) 'Managing agility and productivity in the electronics industry', Industrial Management and Data Systems, Vol. 104, No. 7, pp.567-577.

Hilmola, O-P. (2001) 'Theory of constraints and outsourcing decisions', International Journal of Manufacturing Technology and Management, Vol. 3, No. 6, pp.517-527.

Hilmola, O-P. (2004) 'Enhancing system-wide profitability with new product introduction and throughput accounting', International Journal of Innovation and Technology Management, Vol. 11, No. 3, pp.289-306.

Hilmola, O-P., Helo, P. and Holweg, M. (2005) 'On the outsourcing dynamics in the electronics sector: the evolving role of the original design manufacturer', University of Cambridge, Working Paper Series, No. 04.

Liu, Y. and Basson, A.H. (2004) 'Case study using COM (OLE) to link CAD and manufacturing cost estimation software', COMA'04, International Conference on Competitive Manufacturing, Stellenbosch, South Africa, ISBN 0-7972-1018-0, pp.168-174.

Lu, L.Y.Y., Hung, S-W. and Yang, C. (2004) 'Successful factors of the fabless IC industry in Taiwan', International Journal of Manufacturing Technology and Management, Vol. 6, Nos. 1/2, pp.98-111.

Mevellec, P. (2000), 'Le coût global, nouvelle frontière du calcul de coûts', FINÉCO, Vol. 10.

Mevellec, P. and Lebas, M. (1998) Managing Simultaneously Cost and Value: The Challenge; The Role of Management Accounting in Creating Value, New York: Publication of IFAC, pp.13-25.

Perrin, J. (1996) 'Cohérence, pertinence et évaluation économique des activités de conception', in ECOSIP (ED). Economica, ISBN 2-7178-3023-1.

Perry, N. and Bernard, A. (2003) 'Cost objective PLM and CE', Concurrent Engineering 2003: the Vision for the Future Generation in Research and Applications, ISBN 905809623 8, pp.817-822, Title Volume 1 - Enhanced Interoperable Systems, in J. Cha et al. (Eds). (C) 2003 Swets \& Zeitlinger, Lisse.

Perry, N., Mauchand, M. and Bernard, A. (2004) 'Costs models in design and manufacturing of sand casting products', in A. Bramley, D. Brissaud, D. Coutellier and C. McMahon (Eds). IDMME'2004 Book: Advances in Integrated Design and Manufacturing in Mechanical Engineering, Kluwer Academic Press.

Petitdemange, C. (1991) La maîtrise de la valeur - La gestion de projet et l'ingénierie simultanée, Paris-La Défense, Afnor Gestion, ISBN - 2-12-475021-6.

Protégé (2005) Ontology Editor and Knowledge-Base Framework, Available at: http://protege. stanford.edu/.

Rehman, S. and Guenov, M.D. (1998) 'A methodology for modelling manufacturing costs at conceptual design', Computers Industrial Engineering, Vol. 35, Nos. 3/4, pp.623-626, ISSN 0360-8352.

Riedel, T., Wahl, M.G. and Ambler, T. (1999) Costs Analysis Linking Design, Test \& Maintenance, European Test Workshop Constance.

Sheu, C., Chen, M-H. and Kovar, S. (2003) 'Integrating ABC and TOC for better manufacturing decision making', Integrated Manufacturing Systems, Vol. 14, No. 5, pp.433-441.

Wahl, M.G., Rahman, M. and Ambler, T. (2000b) 'Economics modelling for long lasting systems', 34th Annual Conference/Symposium on Engineering and Technical Management, Dallas, September.

Wahl, M.G., Villareal, E.D. and Rahman, M. (2000a) 'A model based universal cost optimizer', 1st Austin Workshop on Engineering Management, Austin. 